\title{
Improving Comprehensive Medication Review Acceptance by Using a Standardized Recruitment Script: A Randomized Control Trial
}

\author{
Alexander Miguel, PharmD, CGP; Anna Hall, PharmD, BCACP; Wei Liu, MD, PhD; \\ Jeremy Garrett, PharmD; Angel Ballew, PharmD, MBA, BCPP; Tsu-Hsaun Yang, PharmD; \\ and Richard Segal, PhD
}

\begin{abstract}
BACKGROUND: The Centers for Medicare \& Medicaid Services (CMS) require prescription drug plan sponsors to offer a comprehensive medication review (CMR) annually to eligible beneficiaries through the plans' Medication Therapy Management Programs (MTMPs). In 2011, the Pharmacy Quality Alliance endorsed the CMR completion rate as a quality measure for MTMPs, and CMS has adopted the measure into the 2016 CMS star ratings. CMS star ratings are used to describe the quality of plans to assist Medicare plan enrollees in choosing a plan and to determine quality bonus payments for Medicare Advantage plans. Star ratings are measured on a scale of 1 to 5 , with 5 being the highest possible rating for an individual measure. Currently, the majority of plans score 2 stars or less on the CMR completion rate measure.
\end{abstract}

OBJECTIVE: To demonstrate the effectiveness of a standardized CMR recruitment script emphasizing the benefits of the service to increase acceptance of CMR offers among beneficiaries of a Medicare prescription drug plan.

METHODS: A CMR recruitment script, shaped by the Health Belief Model, was developed based on a previous pilot study. The original script described the CMR service but did not emphasize key benefits or barriers from the beneficiary perspective. The updated script aimed to enhance beneficiary understanding of the CMR service, explain the benefits from the beneficiary perspective, and address potential barriers to accepting the service. The updated script was tested during the 2012 MTMP enrollment in a randomized controlled experiment, using the original script as the control. The CMR service was offered to MTMP members via phone calls by live call agents who spoke with members who answered, using 1 of the 2 scripts. Both scripts asked members if they were willing to have a pharmacist call them back and perform a CMR at a later date. Two call attempts were made to all eligible beneficiaries. If contact was not made after 2 unsuccessful outreach attempts, a computer-generated voicemail message was left, and an informational letter regarding the MTMP and CMR was subsequently mailed. CMR acceptance rates, defined as the proportion of beneficiaries who spoke with a call agent and agreed to participate in the CMR service, divided by the total number of beneficiaries contacted who confirmed their membership with the Part D plan, were compared between those exposed to the original script and those exposed to the updated script. Multivariate logistic regression was employed to examine factors that may have influenced members' decisions regarding the offer to participate in CMRs.

RESULTS: There were 105,701 beneficiaries in the first quarter of the MTMP 2012 enrollment who were eligible for the MTM service. Approximately 10\% of eligible beneficiaries answered the live calls and listened to the scripts. On average, members who responded to calls were aged 68.9 years, prescribed 10.5 chronic medications, and had 6 different chronic conditions. Among members who answered the calls, $52.9 \%$ were exposed to the original script, and $47.1 \%$ heard the updated script. For the updated script, $48.2 \%$ of the members accepted the offer to be subsequently contacted by a pharmacist to complete the CMR, whereas $38.1 \%$ of members exposed to the original script agreed to the CMR offer. Logistic regression results indicated that members who received the updated script were $1.58(95 \% \mathrm{Cl}=1.45-1.72)$ times more likely to accept the CMR offer compared with those who received the original script. Among other factors, increased number of chronic medications $(0 R=1.038,95 \%$ $\mathrm{Cl}=1.020-1.057)$, increased number of disease conditions (OR=1.039, $95 \%$ $\mathrm{Cl}=1.014-1.064)$, and previous involvement in the MTMP were positively associated with acceptance of the CMR offer.

CONCLUSIONS: The updated script outperformed the original script in promoting member willingess to participate in a CMR by describing key components and emphasizing benefits of participation. CMR engagement remains a challenge for Medicare plan sponsors. This study demonstrates that to overcome common hurdles to CMR engagement, sponsors should seek strategies to educate members regarding MTM programs and the benefits and components of a CMR.

J Manag Care Spec Pharm. 2017;23(1):13-21

Copyright $\odot 2017$, Academy of Managed Care Pharmacy. All rights reserved.

\section{What is already known about this subject}

- Many medication therapy management (MTM)-eligible beneficiaries do not understand MTM services or the potential benefits of participating in a comprehensive medication review (CMR).

The Centers for Medicare \& Medicaid Services' MTM CMR Completion Rate Measure debuted in 2016 as the first Medication Therapy Management Program (MTMP)-specific quality measure for Medicare Advantage prescription drug plans (MAPD) and Medicare Part D plans.

Factors associated with Medicare members' decisions to accept CMRs include convenience, knowledge of CMR out-of-pocket costs, poorer health status, and physician support of and collaboration with the MTM pharmacist.

\section{What this study adds}

This study is the first randomized controlled trial that explores the use of a telephonic script to describe CMRs and their potential benefits in order to persuade Medicare beneficiaries to participate in CMRs.

This study presents characteristics of a CMR recruitment script that can increase member willingness to participate in a CMR. Insights are presented into common barriers or reasons members choose not to participate in CMRs. 
$\mathrm{T}$ he Centers for Medicare \& Medicaid Services (CMS) require Medicare Advantage Prescription Drug plan (MAPD) and stand-alone Medicare Part D plan (PDP) sponsors to offer a comprehensive medication review (CMR) annually to eligible beneficiaries through the plans' Medication Therapy Management Programs (MTMPs). Each year, CMS specifies eligibility criteria for member inclusion in MTMPs. Inclusion is based on number of chronic medications, chronic disease state, and projected annual drug costs of Part D medications. CMS defines a CMR as "a systematic process of collecting patient-specific information; assessing medication therapies to identify medication-related problems; developing a prioritized list of medication-related problems; and creating a plan to resolve them with the patient, caregiver, and/or prescriber." In addition, CMRs should be interactive, patient-centric, and conducted in person or via telehealth. ${ }^{2}$ Although sponsors are required to offer CMRs to eligible beneficiaries, these beneficiaries are not required to participate. In fact, of all eligible members, the CMR completion rate averaged only $9.6 \%$ nationally in 2012. However, the CMR completion rate has now become a CMS star rating measure. ${ }^{3}$

In 2011, the Pharmacy Quality Alliance endorsed "the completion rate for comprehensive medication review" as a quality measure for MTMPs, and by 2013, CMS began reporting the CMR completion rate as a display measure on its website. ${ }^{4}$ In 2016, the MTM CMR Completion Rate Measure was adopted as a star rating measure for MAPD plans and stand-alone PDPs. This process measure is defined as the percentage of medication therapy management (MTM) program enrollees who received a CMR during the reporting period. Specifically, the numerator includes the number of beneficiaries from the denominator who received a CMR at any time during the MTM enrollment period in the reporting period. The denominator includes the number of beneficiaries who were aged at least 18 years as of the beginning of the reporting period, who were enrolled in the MTMP at least 60 days during the reporting period, and who meet the contracts' specified targeting criteria as required by CMS. ${ }^{5}$

Measures assigned a star rating are used by CMS to describe the quality of a plan and to determine quality bonus payouts for Medicare Advantage plans. Star ratings vary from 1 to 5 stars on individual quality measures, as well as an overall quality rating for each plan. A 5-star rating is considered the highest possible rating for a plan sponsor. In 2016, only 4-and 5-star rated MAPD plans received quality bonus payments. CMS has the authority to terminate plans that consistently score low on star ratings. Additionally, a sponsor's star ratings are reported on the Medicare Plan Finder website, which may serve to encourage enrollees to select higher rated plans. ${ }^{6}$ The latter issue is of particular importance to stand-alone PDPs, since they are not eligible for bonus payments under the current model and depend on membership as part of their financial success. Currently, the majority of plan sponsors are struggling to increase CMR participation, with the majority of MAPD and PDP plans scoring 2 stars or less on this measure. ${ }^{7}$ With the recent adoption of CMR completion as a star measure, it will be prudent for plan sponsors to discover successful strategies to increase CMR participation so as to improve their overall star ratings.

Given the importance of increasing MTM participation, researchers, Part D plan sponsors, and MTM providers continue to explore reasons why members choose to accept or decline MTM services, as well as ways to increase participation. Previous studies have shown that many MTM-eligible beneficiaries do not understand MTM services or how they might benefit from a CMR. ${ }^{8-11} \mathrm{~A}$ positive association was found between CMR participation and use of the Medication User Self-Evaluation (MUSE) tool, which engages beneficiaries by communicating their personal likelihood of benefiting from a CMR. ${ }^{12}$ In a subanalysis of the larger study using the MUSE tool, Farris et al. (2016) recently reported a positive association between Part D beneficiaries reporting poorer health status and subsequently receiving a CMR. ${ }^{13}$ Doucette et al. (2013) have also reported factors that affect beneficiary decisions to receive CMRs. ${ }^{14}$

The Health Belief Model (HBM), developed by social psychologists in the 1950s, has been adapted to explore a variety of health behaviors. The HBM focuses on how an individual's attitudes and beliefs influence health behaviors and decision making. As such, this model can offer a useful framework for explaining how perceptions held by Part D beneficiaries about benefits and concerns associated with CMRs could explain why members accept or decline a CMR offer. ${ }^{15}$

In 2012, WellCare Health Plans (WellCare), a national MAPD and PDP sponsor, contracted with the University of Florida's MTM Communication and Care Center for provision of telephonic CMRs for the plans' MTMP-eligible beneficiaries. Members who were eligible for the MTMP were identified by WellCare and automatically enrolled into the program on a quarterly basis. Each active MTMP member was offered the opportunity to participate in a telephonic CMR with an MTM provider via phone using a standardized call script. This study reports on WellCare's program and is the first randomized controlled experiment designed to demonstrate the effectiveness of a standardized script in increasing CMR acceptance rate by applying the principles of HBM and emphasizing the benefits of and potential barriers to receiving a CMR.

\section{Methods}

\section{Study Design}

This study was a randomized controlled experiment comparing the effectiveness of 2 telephonic participation scripts that were used to offer MTMP members an opportunity to participate in CMRs. The study was conducted in collaboration with WellCare and was approved by the University of Florida's 
Institutional Review and Privacy Board. In late 2011, a pilot study was first conducted with 56 randomly selected Part D beneficiaries who qualified for the MTMP. Recruitment phone calls for CMRs were made with these beneficiaries using a standardized script that had been previously used by the plan for CMR recruitment. Reactions and responses to the script were observed and documented. These noted observations and responses were analyzed and categorized according to the dimensions of the HBM. The pilot revealed that many beneficiaries had difficulty understanding the MTMP and purpose of the CMR. The original script was updated so as to address these issues, emphasize the value of a CMR, and address perceived benefits and barriers to accepting the service. This updated script was tested in this pilot phase with 20 community-dwelling adults who were aged 55 years or older and taking multiple medications. All 20 participants were able to comprehend and recall what a CMR entails after listening to the updated script, and $75 \%$ of the participants expressed agreement to participate in a CMR when offered in the interview.

The original and updated scripts were then used in this study to contact members of the larger WellCare MTMP population to make CMR recruitment calls. The calls were made during the second quarter of 2012 by a call vendor experienced in health care survey research and call center support services. A database containing the contact information of eligible MTMP beneficiaries was compiled by WellCare. For those beneficiaries lacking a valid telephone number, the call vendor searched a national telephone database in an attempt to identify those phone numbers. Recruitment calls were made by live call agents between 10:00 AM and 8:00 PM local time, 7 days a week, and were offered in either English or Spanish. When the call was answered by the beneficiary or his/her designated representative, the call agent then proceeded with the CMR recruitment following the call script. If the beneficiary could not be reached, a second call attempt occurred on a different day. After 2 unsuccessful outreach attempts, a computergenerated voicemail message was left, and an informational letter regarding the MTMP and CMR was subsequently mailed.

\section{Patient Eligibility}

All Medicare beneficiaries were automatically enrolled in the MTMP if they were expected to meet the following criteria for the plan year: (a) have at least 3 chronic medical conditions; (b) take at least 7 chronic maintenance medications per month that are covered under Part D; and (c) incur a projected drug expense of over $\$ 3,100.20$ (including copays/coinsurance and changes to insurance plan) for the plan year. Beneficiaries eligible for MTMP were identified by WellCare and were automatically enrolled into the program on a quarterly basis. Beneficiaries who had received CMRs in the previous year and again qualified for the MTMP in the current year would be automatically enrolled in the program.

\section{Intervention and Randomization}

Two call scripts were used for patient recruitment: the original script (control group) and the updated script (intervention group). The original script was similar to the script that WellCare had used for CMR recruitment in 2011, but it contained additional features to enhance member response, such as a call back scheduling option. The original script first confirmed the membership status of the beneficiary with the Part D plan, proceeded with the member's enrollment status with the MTMP, and then offered the opportunity to accept the offer of a CMR to those members who confirmed their participation in the MTMP. This script described the CMR service but did not emphasize key benefits or address potential barriers from the perspective of the member.

The updated script was constructed using WellCare's previous recruitment script from 2011 as a framework and incorporated elements of the HBM. ${ }^{15}$ The updated script aimed to increase beneficiary awareness of the benefits of receiving CMRs by helping them to understand the CMR service. This updated script incorporated textual changes to provide members with more information about CMRs and structural changes to maximize the number of members who agreed to participate in a CMR (Table 1).

It was hypothesized that previous exposure by beneficiaries to the MTMP and/or CMR could be an important factor that could affect the perceived value of these services and would affect the likelihood of beneficiaries to participate in subsequent CMRs. Therefore, those beneficiaries eligible for the MTMP during the first quarter of 2012 were stratified into 5 categories: (1) new members, (2) returning members who had previously received a CMR, (3) returning members who had previously accepted a CMR offer but did not actually receive a CMR, (4) returning members who had previously declined a CMR offer, and (5) returning members who did not previously respond to the CMR offer. The latter 4 categories were established for beneficiaries who were in the WellCare MTMP in 2011 and were based on their CMR recruitment status from that year. The randomization code was prepared using computer-generated random numbers. Eligible beneficiaries were assigned with equal probability to receive either the original script or the updated script in each stratified category (Table 2). Neither the call agents nor the beneficiaries were aware that different scripts were used.

\section{Study Outcomes}

The primary objective of this study was to determine whether the updated script increased the acceptance of a CMR offer compared with the original script among Medicare prescription drug plan beneficiaries. Thus, the primary dependent variable of interest was the CMR acceptance rate, defined as the proportion of beneficiaries who spoke with a call agent and agreed to participate in the CMR service, divided by the total 


\begin{tabular}{l|l}
\hline TABLE 1 Comparison of Original Script and \\
Updated Script
\end{tabular}

number of beneficiaries contacted who confirmed their membership with the Part D plan.

A secondary objective of this study was to identify the potential barriers to receiving a CMR and increasing the CMR acceptance rate. A logistic regression model was used to identify factors that were associated with plan members' agreement to participate in the CMR service. Member data on predictor variables for the model consisted of baseline demographics (age, gender, geographical location, and language); health plan features (low-income subsidy category and health plan type); member status (new members, returning members who accepted CMR, returning members who declined CMR, returning members who received CMR, and returning members without response); total chronic medication count; total disease count; day of call (weekday/weekend); time of call (AM/PM); and the presence or absence of the following medical conditions defined by CMS prescription drug hierarchical condition category (RxHCC) codes: diabetes, psychological disorders, chronic kidney disease, transplantation, cardiovascular disease, chronic lung disease, and hypertension. ${ }^{16}$

\section{Statistical Analysis}

A descriptive univariate analysis was performed to describe the baseline characteristics of the study population. In the univariate analysis, differences in baseline member characteristics between the 2 groups were assessed using the chi-square test for categorical variables and the independent Student t-test for continuous variables. Total disease count and total chronic medication count were assessed using the Mann-Whitney test for nonparametric data, since distributions of these variables were not normal based on the quantile-quantile plot.

Multivariate analyses for predictive factors associated with CMR service participation were performed using a stepwise logistic regression analysis. A conservative approach was used for entry in the multivariate model by selecting variables with $P<0.2$ in the univariate analyses to preserve potentially important predictors that may have been lost if $P \leq 0.05$ had been used as the threshold for entry in the model. The criterion for remaining in the final model was at the significance level of 0.05. The odds ratio (OR) and 95\% confidence interval (CI) was calculated for each independent predictor variable relative to CMR participation that remained in the final model.

For the final model, discrimination was evaluated using the c-statistic, equivalent to the area under the receiver operating characteristic curve. C-statistics are used to compare the goodness of fit of the logistic regression model and represent the probability that the prediction of outcome is better than chance. The bootstrap method was used to calculate the 95\% CIs around these estimates. ${ }^{17}$ The logistic regression models were repeated 1,000 times, and 95\% CIs for the c-statistics were estimated. Model calibration was assessed using the Hosmer-Lemeshow goodness-of-fit test, which estimates the agreement between predicted probabilities and observed outcomes. Finally, stratified analyses were conducted to examine if any special predictor variables presented in disease-state subgroups at the time of MTMP enrollment. All tests were 2-sided and were performed using SAS software version 9.2 (SAS Institute, Cary, NC).

\section{Results}

After randomization, 52,851 and 52,850 subjects were assigned to the original script and the updated script, respectively. Selected baseline characteristics are reported for the 105,701 subjects in Table 2 . The mean age of the population was 71 years, and $63 \%$ of the subjects were female. Over $90 \%$ of the members were enrolled in a PDP, while less than $10 \%$ had prescription and medical coverage administered by WellCare through a Medicare Advantage product. Almost 99\% of the members qualified for low-income subsidy.

Of the total subjects in each group, 5,971 subjects assigned to the original script and 5,335 subjects assigned to the updated script had valid telephone numbers and were reached by a call agent. Of the subjects reached, 5,289 assigned to the original script and 4,709 assigned to the updated script confirmed that 
TABLE 2 Baseline Demographic and Clinical Characteristics of Study Participants ${ }^{a}$

\begin{tabular}{|c|c|c|c|c|c|c|c|c|}
\hline \multirow[b]{2}{*}{ Characteristics } & \multicolumn{4}{|c|}{ Test Population } & \multicolumn{4}{|c|}{ Initial Population } \\
\hline & \multicolumn{2}{|c|}{ Original Script } & \multicolumn{2}{|c|}{ Updated Script } & \multicolumn{2}{|c|}{ Original Script } & \multicolumn{2}{|c|}{ Updated Script } \\
\hline Total number & \multicolumn{2}{|c|}{5,289} & \multicolumn{2}{|c|}{4,709} & \multicolumn{2}{|c|}{52,851} & \multicolumn{2}{|c|}{52,850} \\
\hline Age, years [SD] & 69.4 & [11.9] & 69.1 & {$[11.7]$} & 70.9 & {$[13.0]$} & 70.7 & [12.9] \\
\hline Female, $\mathrm{n}(\%)$ & 3,513 & $(66.5)$ & 3,195 & $(67.9)$ & 33,430 & $(63.3)$ & 33,438 & $(63.3)$ \\
\hline \multicolumn{9}{|l|}{ Geographic region, n (\%) } \\
\hline Midwest & 852 & (16.1) & 742 & (15.8) & \multicolumn{2}{|c|}{ NA } & \multicolumn{2}{|c|}{ NA } \\
\hline Northeast & 857 & $(16.2)$ & 769 & $(16.4)$ & \multicolumn{2}{|c|}{ NA } & \multicolumn{2}{|c|}{ NA } \\
\hline South & 2,251 & $(42.6)$ & 2,057 & $(43.7)$ & \multicolumn{2}{|c|}{$\mathrm{NA}$} & \multicolumn{2}{|c|}{ NA } \\
\hline West & 1,324 & $(25.1)$ & 1,135 & $(24.1)$ & \multicolumn{2}{|c|}{ NA } & \multicolumn{2}{|c|}{ NA } \\
\hline Unknown & 5 & $(0.05)$ & 6 & $(0.06)$ & \multicolumn{2}{|c|}{ NA } & \multicolumn{2}{|c|}{ NA } \\
\hline \multicolumn{9}{|l|}{ Plan type, n (\%) } \\
\hline Prescription drug coverage only & 4,513 & (85.4) & 3,992 & (84.9) & 48,285 & (91.4) & 48,295 & (91.4) \\
\hline Prescription and medical coverage & 771 & (14.6) & 711 & (15.1) & 4,566 & $(8.6)$ & 4,555 & $(8.6)$ \\
\hline Low-income subsidy, n (\%) & & & & & & & & \\
\hline Yes & 5,151 & $(97.5)$ & 4,573 & $(97.2)$ & 52,095 & $(98.6)$ & 52,126 & $(98.6)$ \\
\hline No & 133 & $(2.5)$ & 130 & $(73.7)$ & 756 & $(1.4)$ & 724 & $(1.4)$ \\
\hline Long-term care resident, $\mathrm{n}(\%)$ & 53 & $(1.0)$ & 42 & $(0.9)$ & 5,114 & $(9.7)$ & 5,117 & $(9.7)$ \\
\hline Language, $\mathrm{n}(\%)$ & & & & & & & & \\
\hline English & 4,081 & $(77.2)$ & 3,645 & $(77.5)$ & & & & \\
\hline Spanish & 319 & $(6.0)$ & 295 & $(6.3)$ & & & & \\
\hline Unknown & 884 & $(16.7)$ & 763 & $(16.2)$ & & & & \\
\hline Member status, n (\%) & & & & & & & & \\
\hline New member & 460 & $(8.7)$ & 398 & $(8.5)$ & 6,025 & $(11.4)$ & 6,026 & $(11.4)$ \\
\hline Returning members who accepted CMR in 2011 & 459 & $(8.7)$ & 404 & $(8.6)$ & 2,276 & $(4.3)$ & 2,275 & $(4.3)$ \\
\hline Returning members who declined CMR in 2011 & 1,370 & $(25.9)$ & 1,286 & $(27.3)$ & 5,992 & $(11.3)$ & 5,993 & $(11.3)$ \\
\hline Returning members with no response in 2011 & 2,995 & $(56.7)$ & 2,613 & $(55.6)$ & 36,979 & $(70.0)$ & 36,979 & $(70.0)$ \\
\hline Returning members who received CMR in 2011 & 0 & $(0)$ & 2 & $(0.04)$ & 1,578 & $(3.0)$ & 1,578 & $(3.0)$ \\
\hline Chronic disease count, mean [SD] & 6.4 & {$[2.5]$} & 6.4 & {$[2.5]$} & 3.9 & {$[3.8]$} & 3.9 & {$[3.8]$} \\
\hline Chronic medication count, mean [SD] & 10.5 & {$[2.7]$} & 10.5 & {$[2.7]$} & 6.4 & {$[5.8]$} & 6.4 & {$[5.8]$} \\
\hline Comorbid conditions, $\mathrm{n}(\%)$ & & & & & & & & \\
\hline Diabetes & 3,315 & $(62.7)$ & 2,996 & $(63.7)$ & 32,694 & $(61.9)$ & 32,826 & $(62.1)$ \\
\hline Psychological disorders & 1,676 & $(31.7)$ & 1,593 & $(33.9)$ & 18,620 & $(35.2)$ & 18,828 & $(35.6)$ \\
\hline Chronic kidney disease & 1,247 & $(23.6)$ & 1,174 & $(25.0)$ & 12,444 & $(23.5)$ & 12,358 & $(23.4)$ \\
\hline Cardiovascular diseases & 3,321 & $(62.9)$ & 2,962 & $(63.0)$ & 32,177 & $(60.9)$ & 31,978 & $(60.5)$ \\
\hline Hypertension & 3,159 & $(59.8)$ & 2,829 & $(60.2)$ & 30,298 & $(57.3)$ & 30,626 & $(57.9)$ \\
\hline Asthma/COPD & 2,232 & $(42.2)$ & 1,893 & $(40.3)$ & 19,810 & $(37.5)$ & 19,664 & $(37.2)$ \\
\hline Day of week when call was made, $\mathrm{n}$ (\%) & & & & & & & & \\
\hline Monday-Friday & 3,834 & $(72.3)$ & 3,745 & $(79.6)$ & & & & \\
\hline Saturday or Sunday & 1,450 & $(27.4)$ & 958 & $(20.4)$ & & & & \\
\hline Call attempt made in the morning, ${ }^{b} \mathrm{n}(\%)$ & & & & & & & & \\
\hline Yes & 279 & $(5.3)$ & 598 & $(12.7)$ & & & & \\
\hline No & 5,005 & $(94.7)$ & 4,105 & $(87.3)$ & & & & \\
\hline $\begin{array}{l}\text { aAll P values for test population original script group } v \\
\text { asthma/COPD, and day of the week when the call was } \\
\text { than } 0.05 \text {. } \\
\text { bMorning: before } 12: 00 \mathrm{pm} \text {. } \\
\text { CMR = comprehensive medication review; COPD = chro }\end{array}$ & $\begin{array}{l}\text { script } \\
\text { of the }\end{array}$ & $\begin{array}{l}\text { was } \\
\text { samp }\end{array}$ & $\begin{array}{l}\text { han } 0.0 \\
P \text { values }\end{array}$ & $\begin{array}{l}\text { ith the } \\
\text { compar }\end{array}$ & $\begin{array}{l}\text { ion of co } \\
\text { f initial }\end{array}$ & $\begin{array}{l}\text { bid psy } \\
\text { ulation }\end{array}$ & $\begin{array}{l}\text { al disoro } \\
\text { tpopula }\end{array}$ & $\begin{array}{l}\text { como } \\
\text { are al }\end{array}$ \\
\hline
\end{tabular}

they were WellCare members. Most baseline characteristics in the test population between the original script and the updated script groups were similar with $P$ values greater than 0.05 . The following characteristics had statistically significant differences $(P<0.05)$ between the 2 groups in the test population: comor- bid psychological disorders, comorbid asthma/chronic obstructive pulmonary disease (COPD), and day of the week when the call was made. Finally, there was no evidence for differences in geographic region, language, and time when the phone call was attempted (Table 2 and Figure 1). 


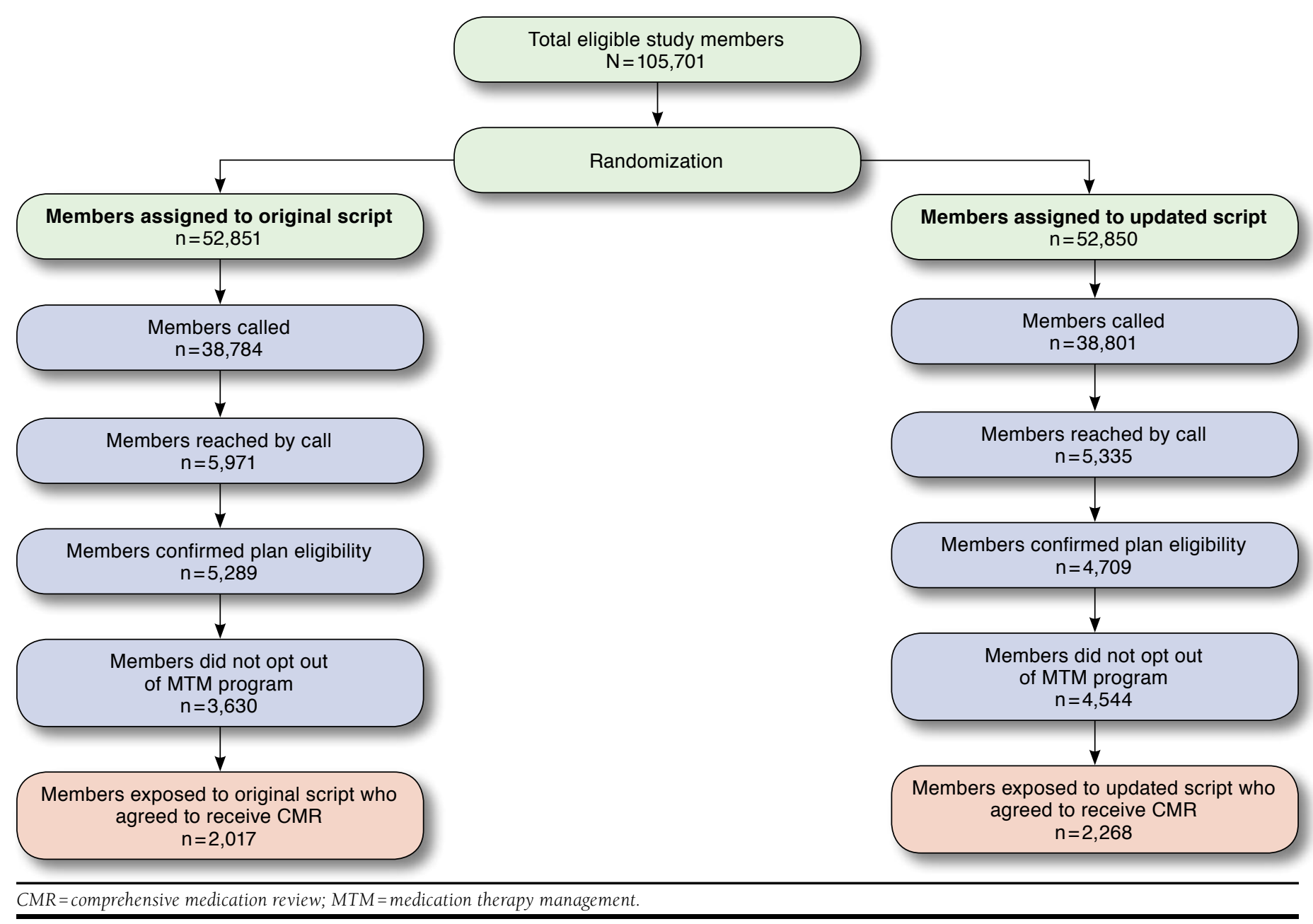

Of the total 9,998 subjects who confirmed their WellCare membership (5,289 for original script and 4,709 for updated script), 2,017 original script subjects and 2,268 updated script subjects agreed to participate in CMRs. Thus, the final CMR acceptance rate was $38.1 \%$ for the original script group and $48.2 \%$ for the updated script group. Subjects who were exposed to the updated script were 58\% more likely to accept the CMR offer than subjects exposed to the original script (adjusted $\mathrm{OR}=1.58,95 \% \mathrm{CI}=1.45-1.72$ ).

Baseline demographic and clinical characteristics were used to create a prediction model for CMR acceptance rates among subjects who confirmed their WellCare membership and had a conversation with a call vendor (Table 3). Female gender (adjusted $\mathrm{OR}=1.03,95 \% \mathrm{CI}=1.01-1.06$ ), total chronic disease count (adjusted $\mathrm{OR}=1.04,95 \% \mathrm{CI}=1.01-1.06$ ), and total chronic medication count (adjusted OR $=1.04$, 95\% CI $=1.02$ 1.06) were significant predictors for members more likely to accept the CMR offer. MAPD members were more likely to accept the CMR offer than PDP members. None of the specific chronic disease conditions (diabetes, psychological disorders, chronic kidney disease, cardiovascular disease, hypertension, and asthma/COPD) appeared to be a significant predictor for CMR participation. Compared with returning members who accepted CMRs in 2011, those returning members who declined the CMR or did not respond to the CMR offer in 2011 were almost 50\% less likely to accept the CMR. The final model had an associated c-statistic of 0.68 , suggesting acceptable discrimination of the prediction model. The $P$ value for the Hosmer-Lemeshow goodness-of-fit test was greater than 0.05 , suggesting that the model was a good fit and appeared to be correctly specified. When the regression analyses were stratified by patient subgroups defined by the presence or absence of specific disease states, the same predictors of CMR participation were also observed. 
TABLE 3 Univariate and Multivariate Analyses of Association Between Independent Predictors and CMR Participation Among Test Population Members Who Confirmed Health Plan Eligibility

\begin{tabular}{|c|c|c|c|}
\hline \multirow{2}{*}{$\begin{array}{l}\text { Characteristics } \\
\text { Updated script vs. original script }\end{array}$} & $\begin{array}{c}\text { Univariate } \\
\text { Odds Ratio } \\
(95 \% \text { CI })\end{array}$ & \multicolumn{2}{|c|}{$\begin{array}{c}\text { Multivariate Adjusted } \\
\text { Odds Ratio } \\
(95 \% \mathrm{CI})\end{array}$} \\
\hline & $(1.44-1.70)$ & 1.58 & $(1.45-1.72)$ \\
\hline Age (years) & $(0.98-1.0)$ & 0.99 & $(0.98-1.0)$ \\
\hline Female & $(0.93-1.11)$ & 1.03 & $(1.01-1.06)$ \\
\hline Total disease count & $(1.04-1.07)$ & 1.04 & $(1.01-1.06)$ \\
\hline Total chronic medication count & $(1.04-1.08)$ & 1.04 & $(1.02-1.06)$ \\
\hline \multicolumn{4}{|l|}{ Low-income subsidy } \\
\hline Yes vs. no & $(0.85-1.44)$ & 1.07 & $(0.82-1.40)$ \\
\hline \multicolumn{4}{|l|}{ Plan type } \\
\hline Prescription drug coverage only & Reference & \multicolumn{2}{|c|}{ Reference } \\
\hline Prescription and medical coverage & $1.59 \quad(1.41-1.79)$ & 1.56 & $(1.38-1.75)$ \\
\hline \multicolumn{4}{|l|}{ Member status } \\
\hline Returning members who accepted CMR in 2011 & Reference & \multicolumn{2}{|c|}{ Reference } \\
\hline New members & $0.48 \quad(0.38-0.60)$ & 0.50 & $(0.40-0.64)$ \\
\hline Returning members who declined CMR in 2011 & $(0.34-0.47)$ & 0.41 & $(0.35-0.49)$ \\
\hline Returning members who did not respond to CMR offer in 2011 & $(0.44-0.59)$ & 0.51 & $(0.44-0.60)$ \\
\hline \multicolumn{4}{|l|}{ Comorbidity } \\
\hline Diabetics & $(1.08-1.29)$ & 1.06 & $(0.96-1.17)$ \\
\hline Psychological disorders & $(1.07-1.27)$ & 1.01 & $(0.91-1.12)$ \\
\hline Chronic kidney diseases & $(1.03-1.24)$ & 1.01 & $(0.91-1.13)$ \\
\hline Cardiovascular diseases & $(0.96-1.14)$ & 0.97 & $(0.87-1.08)$ \\
\hline Hypertension & $(0.87-1.03)$ & 0.96 & $(0.88-1.06)$ \\
\hline Asthma/COPD & $(0.99-1.18)$ & 0.99 & $(0.90-1.09)$ \\
\hline Call was made on weekend vs. weekday & $(0.97-1.18)$ & 1.09 & $(0.99-1.21)$ \\
\hline Call was made in PM vs. AM & $(0.74-0.99)$ & 0.99 & $(0.85-1.14)$ \\
\hline
\end{tabular}

\section{Discussion}

This study demonstrates that to increase Medicare beneficiary participation in MTMP services, specifically CMRs, plan sponsors must develop scripting protocols that more actively engage members by explaining what a CMR is, what the benefits of CMR participation are, and what to expect during the CMR. A survey of Medicare Part D enrollees performed by Law et al. (2008) found that $93 \%$ of respondents were unaware of the terms "MTM" and "medication therapy management," and $70 \%$ felt that they did not need MTM. ${ }^{8}$ Schultz et al. (2012) found that patient focus groups, including those who had received MTM services or had been recruited for services, did not understand what comprehensive MTM services consisted of and perceived them as not needed. ${ }^{18}$ Additionally, a 2009 study conducted across 4 regional community chain pharmacies found that $60 \%$ of participants had never heard of MTM services; $80 \%$ had never had or received a medication therapy review; and $86 \%$ had never received a medication action plan. ${ }^{9}$

The literature examining the HBM has shown us that members must perceive a benefit to themselves before they are willing to undergo a health behavior change such as agreeing to participate in a CMR. ${ }^{15}$ In order to recognize that a potential benefit exists, however, they must first understand what CMRs entail. Since the literature demonstrates that one of the biggest hurdles to successful CMR recruitment is member knowledge of MTM and CMRs and how they can be beneficial, the updated script was designed to incorporate this information into the first moments of the call, immediately following verification of beneficiaries' identities. ${ }^{8}$ Addressing this information at the beginning of the conversation allows the member to then make a more informed decision when the offer to participate is made. This is consistent with the findings of Doucette et al. (2015), which further incorporated personal information of beneficiaries to estimate the likelihood of the CMR to benefit the individual. ${ }^{12}$

Recent surveys of Medicare beneficiaries found 2 common barriers to participation: concerns over the cost of the service and worry that the CMR would take too much time. ${ }^{10,14,18}$ The updated script addresses both of these points by emphasizing that the CMR is a free service and by explicitly describing how long the review should take. Members who declined to participate were given the opportunity to explain why they made that decision, and this information was recorded for use in future research. 
In addition to the content of the script, the order in which questions were presented was different between the original and updated scripts. This proved to be of particular significance. The updated script was designed to increase member exposure to the CMR offer by not providing an early exit opportunity for the members. This proved to be especially beneficial, since $96 \%$ of members exposed to the updated script continued to the point in the script where they were offered the CMR, while $69 \%$ of members hearing the original script reached the CMR offer point. The original script asked members if they would like to continue in the MTMP before specifically offering the CMR, which resulted in a large number of members deciding not to continue with the program and ending the call before listening to the CMR offer. Constructing the script with as few opportunities for members to opt out as possible is a demonstrated strategy to increase member participation. The updated script directly addressed these common barriers by describing key components of the CMR and emphasizing how CMR participation could benefit members who have trouble with their medications.

Other factors associated with increased likelihood to accept the CMR offer included the total number of chronic medications and disease states and plan type. Members with greater number of medications and disease states were slightly more likely to accept the CMR offer. Members receiving 1 more prescription medication or having 1 more disease were, on average, 3\%-4\% more likely to accept the CMR offer. Consistent with other MTMP findings, MAPD members were more likely to accept the CMR offer than PDP members. ${ }^{19}$ This finding may be a result of increased familiarity and plan recognition within the MAPD population. In our experience, members are more likely to recognize the name of their medical coverage provider then their prescription drug coverage provider.

\section{Limitations}

This study has some limitations to be considered. First, this study is limited to initial outreach to MTM-eligible members to ask if they would be willing to accept the offer of a CMR. The study does not offer a follow-up to determine if the members who agreed to participate actually completed a CMR when contacted by the pharmacist for the CMR appointment. Second, while there were statistically significant differences in the test population groups related to comorbid psychological disorders, comorbid asthma/COPD, and day of the week when a call was made, these differences were so small that it was unlikely they translated to a practical difference. Third, data on time to administer the original script in comparison with the updated script were not available. Thus, the correlation of time to administer the script with CMR acceptance was not available for inclusion as a variable in the regression model. A fourth limitation was that if members did not speak English or Spanish they were marked as unable to be reached by the agent conducting the initial outreach call to offer a CMR, and a subsequent phone call was placed using a translator service by the plan to offer a CMR. The outcome of the outreach to nonEnglish- and non-Spanish-speaking members was not captured as part of this study and was estimated to have affected a small percentage of calls. Finally, this study was conducted in an MAPD and PDP population from a 1-plan sponsor, so generalizability to other populations is unknown.

\section{Conclusions}

The updated script outperformed the original script in promoting member agreement to participate in CMRs. The updated script attempted to directly address member apprehension to CMR participation by describing key components of the CMR and emphasizing how CMR participation could benefit them and assist in resolving challenges with their medications. CMR engagement remains a challenge for Medicare plan sponsors. This study demonstrates that to overcome common hurdles to CMR engagement, sponsors must seek strategies to educate members regarding their MTM programs and the benefits and components of CMRs. Further scripting improvement may address common beneficiary concerns and perceived barriers to participating in CMRs.

\section{Authors}

ALEXANDER MIGUEL, PharmD, CGP; ANNA HALL, PharmD BCACP; and JEREMY GARRETT, PharmD, University of Florida MTM Communication and Care Center, Orlando. WEI LIU, MD, PhD; TSU-HSAUN YANG, PharmD; and RICHARD SEGAL, PhD, University of Florida College of Pharmacy, Gainesville. ANGEL BALLEW, PharmD, MBA, BCPP, WellCare Health Plans, Tampa, Florida.

AUTHOR CORRESPONDENCE: Anna Hall, PharmD, BCACP, Director, University of Florida MTM Communication and Care Center, 6550 Sanger Rd., Orlando, FL 32827. Tel.: 407.313.7033; E-mail: ahall@cop.ufl.edu.

\section{DISCLOSURES}

No outside funding supported this study. Research for this study was conducted while Liu was a postdoctoral fellow at the University of Florida. Liu is currently an employee of the U.S. Food and Drug Administration (FDA) The views expressed here are those of the authors and not necessarily those of the FDA. Yang reports receiving a research fellowship funded by WellCare Health Plans at the time of this study. The authors report no other potential conflicts of interest.

Study concept and design were primarily contributed by Yang, Segal, and Miguel, along with Hall, Liu, and Ballew. Miguel, Liu, Yang, Ballew, and Hall collected the data, which were analysed and interpreted primarily by Liu, along with Yang and Segal and assisted by the other authors. The manuscript was written primarily by Miguel, Hall, and Garret, along with Liu, Yang, and Ballew, and revised by Ballew, Segal, Hall, and Miguel, along with Liu and Yang. 


\section{REFERENCES}

1. Centers for Medicare \& Medicaid Services. Memorandum. Correction contract year 2017 medication therapy management program guidance and submission instructions. April 8, 2016. Available at: https://www.cms. gov/Medicare/Prescription-Drug-Coverage/PrescriptionDrugCovContra/ Downloads/Memo-Contract-Year-2017-Medication-Therapy-ManagementMTM-Program-Submission-v-040816.pdf. Accessed November 18, 2016.

2. American Pharmacists Association, National Association of Chain Drug Stores Foundation. Medication therapy management in pharmacy practice: core elements of an MTM service model, version 2.0. March 2008. Available at: http://www.pharmacist.com/sites/default/files/files/core_elements_of_ an_mtm_practice.pdf. Accessed November 18, 2016

3. Pearson CF. Few Medicare beneficiaries receive comprehensive medication review services. Avalere Health. August 7, 2014. Available at: http:// avalere.com/expertise/managed-care/insights/few-medicare-beneficiariesreceive-comprehensive-medication-management-serv. Accessed November 18, 2016.

4. Centers for Medicare \& Medicaid Services. Part C and D performance data. 2013 plan ratings and display measures: 2013 plan ratings technical notes. Available at: http://www.cms.gov/Medicare/Prescription-DrugCoverage/PrescriptionDrugCovGenIn/PerformanceData.html. Accessed November 18, 2016.

5. Centers for Medicare \& Medicaid Services. Part C and D performance data. 2016 star ratings and display measures: 2016 star ratings technical notes. Available at: https://www.cms.gov/medicare/prescription-drugcoverage/prescriptiondrugcovgenin/performancedata.html. Accessed November 18, 2016.

6. Centers for Medicare \& Medicaid Services. Announcement of calendar year (CY) 2017 Medicare Advantage capitation rates and Medicare Advantage and Part D payment policies and final call letter. April 4, 2016. Available at: https://www.cms.gov/Medicare/Health-Plans/MedicareAdvtgSpecRateStats/ Downloads/Announcement2017.pdf. Accessed November 18, 2016.

7. Centers for Medicare \& Medicaid Services. Part C and D performance data. 2016 star ratings and display measures: performance data. Available at: https://www.cms.gov/medicare/prescription-drug-coverage/prescriptiondrugcovgenin/performancedata.html. Accessed November 18, 2016.

8. Law AV, Okamoto MP, Brock K. Perceptions of Medicare Part D enrollees about pharmacists and their role as providers of medication therapy management. J Am Pharm Assoc (2003). 2008;48(5):648-53.
9. Truong HA, Layson-Wolf C, de Bittner MR, Haupt S. Perceptions of patients on Medicare Part D medication therapy management services. J Am Pharm Assoc (2003). 2009;49(3):392-98.

10. Garcia GM, Snyder ME, McGrath SH, Smith RB, McGivney MS. Generating demand for pharmacist-provided medication therapy management: identifying patient-preferred marketing strategies. J Am Pharm Assoc (2003). 2009;49(5):611-16.

11. Kuhn CH, Casper KA, Green TR. Assessing Ohio grocery store patrons perceptions of a comprehensive medication review. J Am Pharm Assoc (2003). 2009;49(6):787-91.

12. Doucette WR, Pendergast JF, Zhang Y, et al. Stimulating comprehensive medication reviews among Medicare Part D beneficiaries. Am J Manag Care. 2015;31(6):e372-78

13. Farris KB, Salgado TM, Aneese N, et al. Effect of clinical and attitudinal characteristics on obtaining comprehensive medication reviews. J Manag Care Spec Pharm. 2016;22(4):388-95. Available at: http://www.jmcp.org/ doi/10.18553/jmcp.2016.22.4.388.

14. Doucette WR, Zhang Y, Chrischilles EA, et al. Factors affecting Medicare Part D beneficiaries' decision to receive comprehensive medication reviews. J Am Pharm Assoc (2003). 2013;53(5):482-87.

15. Health Belief Model. University of Twente. Available at: http://www. utwente.nl/cw/theorieenoverzicht/Theory\%20Clusters/Health\%20 Communication/Health_Belief_Model/. Accessed November 18, 2016.

16. Centers for Medicaid \& Medicare Services. 2012 model software/ICD9-CM mappings. Available at: https://www.cms.gov/Medicare/Health-Plans/ MedicareAdvtgSpecRateStats/Risk-Adjustors-Items/Risk2012.html?DLPage= $1 \& D L E n t r i e s=10 \& D L S o r t=0 \& D L S o r t D i r=$ descending. Accessed November 18, 2016.

17. Carpenter J, Bithell J. Bootstrap confidence intervals: when, which, what? A practical guide for medical statisticians. Stat Med. 2000;19(9):1141-64.

18. Schultz H, Westberg SM, Ramalho de Oliveira D, Brummel A. Patientperceived value of medication therapy management (MTM) services: a series of focus groups. Innov Pharm. 2012;3(4):Article 96. Available at: http:// pubs.lib.umn.edu/cgi/viewcontent.cgi?article $=1098 \&$ context=innovations. Accessed November 18, 2016.

19. Acumen. Medication therapy management in chronically ill populations: final report. Contract \# HHSM-500-2011-00012I/TOT0001. August 2013. Available at: http://innovation.cms.gov/files/reports/mtm_final_report.pdf. Accessed November 18, 2016. 